\title{
Prediction of particulate matter concentration profile in an opencast copper mine in India using an artificial neural
}

\section{network model}

Aditya Kumar Patra ${ }^{\mathrm{a}}$, Sneha Gautam ${ }^{\mathrm{a}}$, Shubhankar Majumdar ${ }^{\mathrm{b}}$, Prashant Kumar ${ }^{\mathrm{c}, \mathrm{d}}$

${ }^{a}$ Department of Mining Engineering, Indian Institute of Technology Kharagpur,

Kharagpur-721302, India

${ }^{b}$ Advanced Technology Development Centre, Indian Institute of Technology Kharagpur,

Kharagpur-721302, India

${ }^{c}$ Departmentof Civil and Environmental Engineering, Faculty of Engineering and Physical Sciences (FEPS), University of Surrey,

Guildford GU2 7XH,United Kingdom

${ }^{\mathrm{d}}$ EnvironmentalFlow (EnFlo) Research Centre, FEPS, University of Surrey, Guildford GU2 7XH, United Kingdom

*Corresponding author: akpatra@ mining.iitkgp.ernet.in 


\section{Abstract}

Particulate matter (PM) is a major pollutant in and around opencast mine areas. The problem of degradation of air quality due to opencast mine is more severe than those in underground mine. Prediction of dust concentration must be known to implement control strategies and techniques to control air quality degradation in the workplace environment. Limited studies have reported the dispersion profile and travel time of PM between the benches inside the mine. In this paper PM concentration has been measured and modeled in Malanjkhand Copper Project (MCP), which is one of the deepest opencast copper mines in India. Meteorological parameters (wind speed, temperature, relative humidity) and $\mathrm{PM}$ concentration in seven size ranges (i.e., $\mathrm{PM}_{0.23-0.3}, \mathrm{PM}_{0.3-0.4}, \mathrm{PM}_{0.4-0.5}$, $\mathrm{PM}_{0.5-0.65}, \mathrm{PM}_{0.65-0.8}, \mathrm{PM}_{0.8-1}$, and $\mathrm{PM}_{1-1.6}$ ) has been measured for 8 days. The results of the field study provide an understanding of the dispersion of the PM generated due to mining activities. This research work presents an approach to assess the exposure of enhanced level of PM concentration on mine workers and its variation with depth. The correlations study shows that concentration of PM during its travel from source to surface is associated with depth. Empirical equations are developed to represent relationships between concentrations of PM and depth. Artificial Neural Network (ANN) model showing the relationship between PM concentration and meteorological parameters has been developed. The performance of the ANN model is evaluated in terms of the correlation coefficient between the real and the forecasted data. The results show strong agreement between the experimental data and the modeled output. The findings of this work are important in understanding fine PM variation inside the mine at the workplace and the associated exposure of mine workers.

Citation details: Patra, A., Gautam, S., Majumdar, S., Kumar, P., 2015. Prediction of particulate matter concentration profile in an opencast copper mine in India using an artificial neural network model. Air Quality, Atmosphere \& Health, doi: 10.1007/s11869-015-0369-9. [PDF] 
Keywords: Opencast mine; Particulate matter; Dispersion; Model performance; Artificial Neural Networks

\section{List of Abbreviation}

ANN: Artificial Neural Network

HCL: Hindustan Copper Limited

MCP: Malanjkhand Copper Project

mRL: meter Reduced Levels

MSE: Mean Square Error

PM: Particulate Matter

RL: Reduced Levels

RMSE: Root-Mean-Square Error

SOS: Sum of Squares

\section{Introduction}

Generation of huge quantity of particulate matter (PM) during mining activities is a subject of immense concern with regard to human health (Pandey et al. 2014; Gautam et al. 2015; Dubey et al. 2012). Earlier studies (Aneja et al. 2012; Hendryx 2009; Tecer et al. 2008; Pless-Mulloli et al. 2001) show that PM from different mining operations contributes to significant adverse effect on human health in the form of black lung, asthma, cardiovascular diseases and lung cancer. PM generated during mining operations at the workplace (called "bench") disperses in the mine by moving to several benches and contributes to the enhanced concentration at different parts of the mine (Gautam and Patra 2015). However, only a few studies have reported detail information about generation, estimation and contribution of PM during mining operations (Marrugo-Negrete et al. 2014; Zhang et al. 2013; Chakraborty et al. 
2002; Ghose and Majee 2001). Therefore, the study of dispersion of PM in and around the mine is very important to assess the level and duration of occupational exposure of PM in the opencast mines.

Generally, the dispersion of PM in the opencast mines depends on local meteorology. Wind flow is the prime mover of the PM from one place to the other. The flow in the mine could be turbulent at one place, whereas laminar at other places (Kakosimos et al., 2011). Richardson (1926) reported wind flow pattern by using of tracer studies in the opencast mines. Other studies have used computational fluid dynamics to estimate the wind flow pattern and dispersion of PM inside the mines (Kakosimos et al. 2011; Blocken et al. 2007; Anderson 1995). Wind direction often changes inside the mine and thus evaluating the role of wind direction on PM level inside the mine is more challenging. With the rise of air temperature, the warm air rises up and it thus carries the PM emitted along with it, resulting in reduction of ground level concentration. The upward movement of the air causes more vertical mixing of air in the atmosphere and thus effects better dispersion and lowers the PM concentration in the mine (Masters 1998). When relative humidity is low, the air is dry and light. Dispersion of PM is more effective in case of dry and light air due to easy vertical mixing (Masters 1998). The wind flow pattern also depends on mine geometry and depth of the mine (Chowdhary 1977). Wind velocity is more in shallow mines than in deep mines and deeper parts of the mine experience poor ventilation than shallow parts (Chowdhary 1977; Peng and Lu 1995). Particles generated at higher depth disperse in an upward direction, before potentially exiting the pit. Therefore, mining operation at deeper parts of the mine contributes to the enhanced PM concentration at higher benches. Further, while the PM travel from lower part of the mine to upper horizons, not all particles travel at same speed and proportion. A coarse particle with 
higher settling velocity settles on mine floor faster than a fine particle and therefore may get depleted from the PM plume as it travels higher (Cooper and Alley 2014). With high mechanization making it possible for the opencast mine to go deeper day by day, dust dispersion study across different horizons in the mine needs attention to assess the workers exposure. However, limited studies have been reported on the dispersion pattern of PM inside the mine with its upward movement from the workplace to the mine boundary (Gautam and Patra 2015; Gautam et al. 2015).

Air pollution modeling is an approach to assess the concentration in the workplace or the surrounding environment (Colard et al. 2015; Reggente et al. 2014; Guttikunda and Kopakka 2014; Kumar et al. 2011). Models are used to generally assess particle concentration in a workplace environment under different meteorological conditions and its outputs are evaluated against the requirements of air quality regulations (Vardoulaki et al. 2003; Viotti et al. 2002; Cohn et al. 2001). Majority of the models for estimation of the concentration of PM in a workplace environment are of empirical in nature where statistical approaches have been used to develop the model (Lal and Tripathy 2012; Vardoulaki et al. 2003). However, statistical approaches sometimes under-perform in predicting the PM concentration from different sources (Sharma et al. 2013; Onder and Yigit 2009). Recently, Artificial Neural Network (ANN) model is being used for predicting the PM concentration (Kumar and Goyal 2013). ANN models are capable of fast processing with several input and output variables (Lal and Tripathy 2012; Kakosimos et al. 2011; Bose and Liang 1998; Anderson 1995). ANN models have been very accurate in many environmental health application areas, especially indoor environment (Skön et al. 2012; Kassomenos et al. 2011), air quality forecasting (Kumar and Goyal 2013; Goyal and Kumar; 2013; Alekseev and Seixas copper mine in India using an artificial neural network model. Air Quality, Atmosphere \& Health, doi: 10.1007/s11869-015-0369-9. [PDF] 
2002), soil analysis (Juang and Chen 1999), water treatment application (Baxter et al. 2002), traffic and vehicular pollution (Nagendra and Khare 2004) and PM concentration prediction from the different sources in the opencast mines (Lal and Tripathy 2012). Earlier studies reported that ANN based air quality models give better results than other statistical models (Kumar and Goyal 2013 ; Lu et al. 2003; Viotti et al. 2002). The advantages of ANN model over statistical model are as follows: (i) it do not require detailed physical models, (ii) it is more compact than large experiment data, (iii) it requires few training points to accurately model the standards, (iv) it can be trained with only a few experiments data, and (v) it can be much more accurate than statistical models, when limited experimental data are available. ANN models have some drawbacks. For example: (i) in order to create training sets to obtain ANN models valid for a large range, intensive measurements have to be performed, and (ii) these models are very poor outside the range of the training set. These drawbacks can be overcome by implementing prior information into the design of neural networks.

Limited studies are available where ANN model has been used to estimate PM concentration inside an opencast mine and relate it with the local meteorological parameters (Lal and Tripathy 2012). In this work, ANN models capable of predicting PM concentration with varying meteorological parameter and depth of working are developed. The relevant data is obtained through an extensive field study in Malanjkhand copper project (MCP) in India. The study aimed at assessing the contribution of mining to the particle concentration and their dispersion as they travel upward from the source located at deeper part of the mine. The ANN model has been tested against the data obtained from this on-field measurement. The results show significant agreement between the experimental results and the ANN model estimate. An empirical relationship between concentrations of PM and depth is also proposed. 


\section{Experimental methodology}

\subsection{Study site}

The study was conducted in MCP of Hindustan Copper Limited (HCL) of India. MCP is the single largest copper deposit in India constituting nearly $80 \%$ of country's reserve and contributing about $70 \%$ of HCL's copper production. The mine has been developed to a depth of $168 \mathrm{~m}$ with average bench height of $12 \mathrm{~m}$. The present pit dimension is $2200 \mathrm{~m} \times 600 \mathrm{~m}$. Surface reduced level (RL; depth or height of a place above a reference datum (usually mean sea level)) at the mine site is $580 \mathrm{~m}$ and the designed ultimate pit depth is $376 \mathrm{mRL}$ (RL expressed in meter). At present mining is being carried out at 400 and $412 \mathrm{mRL}^{\mathrm{u}} \mathrm{sing} 4.6 \mathrm{~m}^{3}$ and $9.2 \mathrm{~m}^{3}$ capacity electric shovels, 50 and $85 \mathrm{~T}$ dumpers and $165 \mathrm{~mm}$ diameter blast-holes. Blast hole drilling, loading and transport of ore at 400 and $412 \mathrm{mRL}$ constitute the source of PM emission. The emission at $412 \mathrm{mRL}$ includes emission from 400 and $412 \mathrm{mRL}$. Therefore in this study, PM concentration at $412 \mathrm{mRL}$ has been considered as the concentration at the source. Out of 13 benches between 412 and $580 \mathrm{mRL}$, sampling was carried out on two benches (448 and $460 \mathrm{mRL}$ ). In addition, PM concentration and local meteorological data were recorded on surface at $580 \mathrm{mRL}$ (Fig. 1).

\subsection{Data collection and Instrumentation}

$\mathrm{PM}$ concentration in seven size ranges (i.e., $\mathrm{PM}_{0.23-0.3}, \mathrm{PM}_{0.3-0.4}, \mathrm{PM}_{0.4-0.5}, \mathrm{PM}_{0.5-0.65}, \mathrm{PM}_{0.65-0.8}, \mathrm{PM}_{0.8-1}, \mathrm{PM}_{1-1.6}$ ) was measured using Grimm aerosol spectrometer (Model 1.108, Grimm, GRIMM Aerosol Technik GmbH \& Co. KG, Germany) (Grimm 2010). Meteorological parameters were recorded by a portable weather station (Spectrum Technologies, Inc., Model Watchdog 2000) 
(Spectrum 2010). Both PM and meteorological data were measured at 1 min interval. The study was conducted during 12 -24 October 2013, at four different depths of the mine (412, 448, 460 and $580 \mathrm{mRL})$ out. At each location sampling was carried out on two consecutive days.

\subsection{ANN Model}

ANN is densely interconnected processing units that utilize parallel computation algorithms. It learns from representative data to simulate special patterns in the dataset without providing special programming modules (Anderson 1995). This allows ANN to learn and adapt to a continuously changing environment. It can be trained to perform a particular function by tuning the values of the weights (connections) between the elements. The training procedure of ANN is performed so that a particular input leads to a certain target output (Alekseev et al. 2002). The input and output layers of any network have numbers of neurons equal to the number of the inputs and outputs of the system, respectively. The architecture of a multi-layer feed-forward neural network have layers between the input and the output layers where a layer represents a set of parallel processing units (or nodes), namely the hidden layer. The main function of the hidden layer is to allow the network to detect and capture the relevant patterns in the data and to perform complex nonlinear mapping between the input and the output variables. The sole role of the input layer of nodes is to relate the external inputs to the neurons of the hidden layer. Hence, the number of input nodes corresponds to the number of input variables. The outputs of the hidden layer are passed to the last (or output) layer, which provides the final output of the network (Baxter et al. 2002; Anderson 1995). Finding a parsimonious model for accurate prediction is particularly critical, since there is no formal method for determining 
the appropriate number of hidden nodes prior to training. Therefore, a trial-and-error method is commonly used for network design (El-Shafie and Noureldin 2011). One of the most important aspects of ANN models is how well the model generalizes the unseen data. The over-fitting problem occurs when an ANN loses its generalization feature. In other words, it cannot generalize the relations which exist between training inputs and their related outputs to the similar hidden patterns of the unobserved data. In such cases, the performance of neural network is measured through regression plot.

The data to be analyzed through ANN model are divided into three parts: (1) Training data: Data presented to the network during training of the model, and the network is adjusted according to its error; (2) Validation data: Data used to measure network generalization and to halt training when generalization stops improving; and (3) Testing data: Data which have no effect on training and therefore it provides an independent measure of network performance during and after training.

To obtain a stable ANN, the total number of network weights and biases cannot exceed the number of training samples. The transfer functions of the hidden layer and output layer neurons are the hyperbolic tangent function and pure identity function, respectively. The error function that has been implemented here is the sum of squares (SOS). The ANN is trained with the help of the error back propagation algorithm. In order to avoid over fitting, the Bayesian framework is used in the training procedure. In this framework, the weights and biases of the network are assumed to be random variables with specified distributions. The regularization parameters are related to the unknown variances associated with these distributions. It can then estimate these parameters using statistical techniques.

Citation details: Patra, A., Gautam, S., Majumdar, S., Kumar, P., 2015. Prediction of particulate matter concentration profile in an opencast copper mine in India using an artificial neural network model. Air Quality, Atmosphere \& Health, doi: 10.1007/s11869-015-0369-9. [PDF] 
It minimizes a linear combination of squared errors and weights, and then determines the correct combination so as to produce a network that generalizes well. The process is called Bayesian regularization.

There can be different neural network structures possible by using different types of neurons and by connecting them differently. A three layered architecture, known as neural interpretation diagram (NID), is used to model the concentration of particles (Fig. 2). The architecture essentially consists of four input neurons such as wind speed, humidity, temperature and mine depth; the meteorological and mine geometry parameters on which the particle dispersion in the mine primarily depends (Cooper and Alley, 2014; Masters 1998; Chowdhary 1977; Peng and Lu 1995) and one output neuron (PM concentration). The rationale for use of an NID is to provide insight into variable importance by visually examining the weights between the layers.

The training algorithm used for ANN is the Levenberg-Marquardt (TRAINLM). The TRAINLM was designed to approach secondorder training speed without having to compute the Hessian matrix. When the performance function has the form of a sum of squares (as is typical in training feed-forward networks), then the Hessian matrix can be approximated as,

$$
\mathbf{H}=\mathbf{J}^{\mathrm{T}} \mathbf{J}
$$

and, the gradient can be computed as,

$$
\mathbf{g}=\mathbf{J}^{\mathbf{T}} \mathbf{e}
$$

Citation details: Patra, A., Gautam, S., Majumdar, S., Kumar, P., 2015. Prediction of particulate matter concentration profile in an opencast copper mine in India using an artificial neural network model. Air Quality, Atmosphere \& Health, doi: 10.1007/s11869-015-0369-9. [PDF] 
Where $J$ is the Jacobian matrix, which contains first derivatives of the network errors with respect to the weights and biases, and $e$ is a vector of network errors. The Jacobian matrix can be computed through a standard back propagation technique that is less complex than computing the Hessian matrix.

The Levenberg-Marquardt algorithm uses this approximation to the Hessian matrix in the following Newton-like update:

$$
\mathbf{x}_{k+1}=\mathbf{x}_{k}-\left[\mathbf{J}^{\mathrm{T}} \mathbf{J}+\mu \mathbf{I}\right]^{-1} \mathbf{J}^{\mathrm{T}} \mathbf{e}
$$

When the scalar $\mu$ is zero, this is a Newton's method, using the approximate Hessian matrix. When $\mu$ is large, this gradient becomes a descent with a small step size. Newton's method is faster and more accurate near an error minimum and therefore the aim is to shift towards Newton's method as quickly as possible. Thus, $\mu$ is decreased after each successful step (reduction in performance function) and is increased only when a tentative step would increase the performance function. In this way, the performance function will be reduced at each iteration of the algorithm.

\section{Results and Discussion}

\subsection{Wind speed and wind direction}


The highest wind speed of $4.72 \mathrm{~m} \mathrm{~s}^{-1}$ was recorded at two bottom most benches (400 and $\left.412 \mathrm{mRL}\right)$ of the mine. The maximum and average wind speed on the surface was the highest among wind speeds all locations on both the days. The wind speed profile on two days at each measurement location during the study period is shown in Figure 3.

Wind speed distribution at $1 \mathrm{~m} \mathrm{~s}^{-1}$ interval shows that most of the time calm conditions (wind speed $<1 \mathrm{~m} \mathrm{~s}^{-1}$ ) prevailed in the mine. Among all study locations, the highest calm condition (89\% and 93\%) was recorded at $448 \mathrm{mRL}$ on both days (Fig. 4). The wind speed at different parts of the mine depends on aspect ratio (length to depth ratio) of the mine and surface wind speed at the mine (Chowdhary 1977). The ground level wind enters the mine and ventilates the top upper part before escaping the mine. Only a part of this air flow with a relatively slower wind speed enters to the deeper parts of the mine and results in poor ventilation. This has resulted in relatively more calm wind conditions $\left(<1 \mathrm{~m} \mathrm{~s}^{-1}\right)$ at 448 and $460 \mathrm{~m}$ level. However with further increase of depth, it changes to complex unsteady flow with recirculation (Chowdhary 1977; Peng and Lu 1995).

Wind direction varied on different benches as well as between the two days of sampling at one bench. The mean wind direction was NE for five days, SE for three days and NW for two days. On three days, wind direction varied widely across all directions. However, on remaining seven days, the wind direction variation was limited to $180^{\circ}$ (Fig. 5)

Citation details: Patra, A., Gautam, S., Majumdar, S., Kumar, P., 2015. Prediction of particulate matter concentration profile in an opencast copper mine in India using an artificial neural network model. Air Quality, Atmosphere \& Health, doi: 10.1007/s11869-015-0369-9. [PDF] 


\subsection{Ambient temperature}

At the start of the experiment in the morning the temperature was $\sim 25{ }^{\circ} \mathrm{C}$ and it increased to $\sim 30{ }^{\circ} \mathrm{C}$ by the end of the experiment at 12:30-13:00 (Fig. 6). The temperature range is typical of the post monsoon (September to November) temperature profile of the area.

\subsection{Relative humidity}

The relative humidity of air at MCP decreased 10\%-40\% during the experiment duration. As expected, it showed an inverse relationship with air temperature (Fig. 7). Low relative humidity at $412 \mathrm{~m}$ on day 2 than at other locations can be attributed to local meteorological conditions on that particular day.

\subsection{PM concentration}

The source at $412 \mathrm{mRL}$ was located at a depth of $168 \mathrm{~m}$ from the surface (580 mRL). Therefore the study site is equivalent to a mine where the source is located at a depth of $168 \mathrm{~m}$ from the surface and the PM concentrations were measured at $168 \mathrm{~m}(412$ mRL), $132 \mathrm{~m}$ (448 mRL), $120 \mathrm{~m}$ (460 mRL) and $0 \mathrm{~m}$ (580 mRL) depth. In summary, higher wind speed results in better dispersion of the PM and hence the predominant calm condition at 448 and $460 \mathrm{~m}$ resulted in poor dispersion and increased background PM concentration, as seen in Figure 8a. It is important to note that fine particles dominated the background concentration at all locations.

The highest background concentration was $8.5 \mu \mathrm{g} \mathrm{m}{ }^{-3}$ for $\mathrm{PM}_{0.23-0.30}$, the smallest among all particle sizes. Earlier studies have also 
reported low fine particle concentration in mine atmosphere with $\mathrm{PM}_{1-2.5}$ and $\mathrm{PM}_{1}$ concentration varying in the range $4-6 \mu \mathrm{g} \mathrm{m}^{-3}$ and 6-8.5 $\mu \mathrm{g} \mathrm{m}^{-3}$ (Gautam et al., 2015). Mining activities predominantly generate coarser particles (Aneja et al., 2012; Onder and Yigit, 2009; Ghose and Majee, 2001). The fine particle concentration in mine atmosphere is therefore low. The concentration of the particles decreased with increase in size (Fig. 8a). This can be attributed to low settling velocity that keeps the fine particles airborne for more duration. As expected, the increment was higher near the source and it decreased with increase of distance from source due to settling of coarse particles (Fig. 8b) (Gautam and Patra 2015; Onder and Yigit 2009).

\subsection{Correlations analysis}

Correlation analysis showed significant correlation between PM concentrations at different benches with the depth of the benches. Relationship between average PM concentration and depth has been established through regression analysis using IBM SPSS statistical package (version 20) (Table 1).

$R^{2}$ values between 46.7 and 65.3 shows a fairly good relationship between depth and concentration. The decrease in coefficients of $x$ (depth) with reduction in particle size indicates slower settling rate of particles of smaller size, corroborating quicker settling of coarse particles than fine particles. The accuracy of the predictor equations are evaluated against the measured data. Figure 9 shows that the model prediction lies within a factor of 2.5 of the measurement.

\subsection{PMforecasting}

Citation details: Patra, A., Gautam, S., Majumdar, S., Kumar, P., 2015. Prediction of particulate matter concentration profile in an opencast copper mine in India using an artificial neural network model. Air Quality, Atmosphere \& Health, doi: 10.1007/s11869-015-0369-9. [PDF] 
The seven types of particle concentration measured at MCP have been utilized to train seven networks with each network corresponding to particle concentration of one size. All seven networks successfully achieved the target $R \approx 85 \%$. Several sets were examined with a maximum of one hidden layer and a maximum of 60 neurons within hidden layer. Therefore, the choice of the number of neurons in hidden layer is based on two statistical performance indices. The first index is the root-mean-square error (RMSE) and the second index is the maximum error. Hence, once the network weights and biases are initialized during the training process, the weights and biases of the network are iteratively adjusted to minimize the network performance function mean square error (MSE) - the average squared error between the network outputs and the target outputs.

\subsection{Importance of input variables}

Inputs are connected to hidden layer via weights. So, the weights that connect variables in an ANN are partially analogous to parameter coefficients in a standard regression model and can be used to describe relationships between variables. The weights dictate the relative influence of information that is processed in the network such that input variables that are not relevant in their correlation with a response variable are suppressed by the weights. The opposite effect is seen for weights assigned to explanatory variables that have strong and positive associations with a response variable.

The input variable whose changes affected the output most was the one that had the most relative influence. Hence, the importance of the different variables in the forecasting model was assessed through sensitivity analysis. This test provided an estimation of the relative importance among the inputs of the neural model and explained the response of the model outputs with respect to the inputs.

Citation details: Patra, A., Gautam, S., Majumdar, S., Kumar, P., 2015. Prediction of particulate matter concentration profile in an opencast copper mine in India using an artificial neural network model. Air Quality, Atmosphere \& Health, doi: 10.1007/s11869-015-0369-9. [PDF] 
One by one, inputs were varied between its mean \pm a user-defined number of standard deviations while all other inputs were fixed at their respective means. In particular, wind speed and temperature interpretation were the most important variables for the $\mathrm{PM}_{0.23}$ to $\mathrm{PM}_{0.65}$ whereas depth and humidity were the information most decisive for the $\mathrm{PM}_{0.8}$ to $\mathrm{PM}_{1.6}$.

\subsection{Prediction of PM concentrations}

The neural network developed and tested for this study was able to forecast the particle concentrations at a site. Comparative results were obtained from an independent set of particle concentrations from a site and a relative error between the ANN model and the datasets (Fig.10). The correlation coefficients $(R)$ between real and forecasted data were very high in all the cases $(R=0.8,0.85$, 0.8, 0.89, 0.69, 0.67 and 0.78 for $\mathrm{PM}_{0.23-0.3}, \mathrm{PM}_{0.3-0.4}, \mathrm{PM}_{0.4-0.5}, \mathrm{PM}_{0.5-0.65}, \mathrm{PM}_{0.65-0.8}, \mathrm{PM}_{0.8-1}, \mathrm{PM}_{1-1.6}$, respectively) (Fig. 11). This indicates strong linear relationship between ANN model outputs and the data obtained from the experiment. Other details of network architectures for each particle dataset are shown in Table 2.

\section{Conclusions}

The measurement and modeling of particle concentration at MCP suggests that a good relationship exists between depth and concentration. The predictor equation showing relationship between depth and concentration has been developed. $R^{2}$ values up to 0.65 shows a fairly good relationship between the depth and concentration with concentration of particles of smaller size decreasing at slower rate than that of bigger particles. This is attributed to the quicker settling of coarse particles than fine particles. The equations 
predicted the PM concentration within a factor of 2.5 of the measurement, which can be considered as a reasonable accuracy for the complex source-emission relationship in an opencast mine.

A supervised neural network (e.g., multilayer feed-forward networks) was used for prediction of fine PM concentration profile inside MCP. This type of network is developed from a set of known variables and the end goal of the model is to match the predicted output

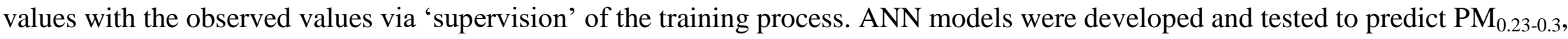
$\mathrm{PM}_{0.3-0.4}, \mathrm{PM}_{0.4-0.5}, \mathrm{PM}_{0.5-0.65}, \mathrm{PM}_{0.65-0.8}, \mathrm{PM}_{0.8-1}, \mathrm{PM}_{1-1.6}$ concentration profiles inside the mine. The result showed that the ANN predictions were close to the experimental values. The $R$ values showing the relationship between the real and the forecasted data of PM varied from 0.67 to 0.85 . The neural network approach was therefore successful in predicting the PM concentration profile inside opencast mine with good accuracy. Thus ANN approach therefore can be used to simplify implementation of acceptable control actions in advance.

The results are based on the data conducted during post monsoon season. Future studies should aim at evaluating the ANN approach for the PM concentration data over a longer period so that monthly and seasonal variations are modeled.

\section{Acknowledgements}


The authors acknowledge Indian Institute of Technology Kharagpur, India, for funding the research under ISIRD grant. Support of the General Manager of the Malanjkhand Copper Project of Hindustan Copper Limited in providing necessary facilities for conducting the field study is duly acknowledged.

\section{References}

Anderson JD (1995) Computational Fluid Dynamics: The Basics with Applications. New York: McGraw-Hill.

Aneja VP, Isherwood A, Morgan P (2012) Characterization of particulate matter (PM10) related to surface coal mining operations in Appalachia. Atmos Environ 54: 496-501.

Alekseev KPG, Seixas JM (2002) Forecasting the air transport demand for passengers with neural modelling. Proceedings of the VII Brazilian Symposium on Neural Networks (SBRN), November 11-14, 2002, Pernambuco, Brazil, IEEE 86-91.

Baxter CW, Stanley SJ, Zhang Q, Smith DW (2002) Developing artificial neural network models of water treatment processes: a guide for utilities. J Environ Engg Sci 1: 201-211.

Blocken B, Stathopoulos T, Carmeliet J (2007) CFD simulation of the atmospheric boundary layer: wall function problems. Atmos Environ 41: 238-252.

Bose NK, Liang P (1998) Neural Network Fundamentals with Graphs, Algorithms and Applications, New Delhi, Tata McGraw-Hill.

Juang HC, Chen CJ (1999) CPT-Based liquefaction evaluation using artificial neural networks. Computer-Aided Civil Infrastructure Engg 14, 221-229.

Chakraborty MK, Ahmad M, Singh RS, Pal D, Bandopadhyay C, Chaulya SK (2002) Determination of the emission rate from various open-cast mining operations. Environ Model Soft 17: 467-480.

Chowdhary KK (1977) An experimental and theoretical investigation of turbulent separated reattached and redeveloped flows with transverse rectangular cavities. [Ph.D. thesis], New Delhi: Indian Institute of Technology Delhi.

Citation details: Patra, A., Gautam, S., Majumdar, S., Kumar, P., 2015. Prediction of particulate matter concentration profile in an opencast copper mine in India using an artificial neural network model. Air Quality, Atmosphere \& Health, doi: 10.1007/s11869-015-0369-9. [PDF] 
Cohn RD, Eder BK, Leduc SK, Dennis RL (2001) Development of an aggregation and episode selection scheme to support the models-3 community multiscale air quality model. J Appl Meteo 40: 210-228.

Colard S, O'Connell G, Verron T, Cahours X, Pritchard JD (2015) Electronic Cigarettes and Indoor Air Quality: A Simple Approach to Modeling Potential Bystander Exposures to Nicotine. Int J Environ Res Public Health 12(1): 282-299.

Cooper CD, Alley FC (2014) Chapter 3: Particulate Matter. Air Pollution Control - A design approach (4 ${ }^{\text {th }}$ Edition), Illinois: Waveland Press Inc., pp. 126.

Dockery DW, Pope CA (1994) Acute respiratory effects of particulate air pollution. A Revi Pub heal 15: 107-32.

Dubey B, Pal AK, Singh G (2012) Trace metal composition of airborne particulate matter in the coal mining and non-mining areas of Dhanbad Region, Jharkhand, India. Atmos Pollut Res 3: 238-246.

El-Shafie A, Noureldin A (2011) Generalized versus non-generalized neural network model for multi-lead inflow forecasting at Aswan High Dam. Hydrol Earth Syst Sci 15: 841-858.

Gautam S, Kumar P, Patra AK (2015) Occupational exposure to particulate matter in three Indian opencast mines. Air Qual Atmos Health (DOI: 10.1007/s11869-014-0311-6).

Gautam S, Patra AK (2015) Dispersion of particulate matter generated at higher depths in opencast mines. Environ Tech Innov 3:11-27.

Ghose MK, Majee SR (2001) Air pollution caused by opencast mining and its abatement measures in India. J Environ Manage 63 (2): $193-202$.

Goyal R, Kumar P (2013) Indoor-outdoor concentrations of particulate matter in nine microenvironments of a mixed used commercial building in megacity Delhi. Air Qual Atmos Health 6: 747-757.

Grimm (2010) Operation manual of Portable Laser Aerosol spectrometer and dust monitor (Model 1.108/1.109). GRIMM Aerosol Technik GmbH \& Co. KG, Ainring, Germany.

Hendryx M (2009) Mortality from heart, respiratory, and kidney disease in coal mining areas of Appalachia. Int Arch Occup Environ Health 82: $243-249$.

Kakosimos KE, Assael MJ, LioumbasJS, Spiridis AS (2011) Atmospheric dispersion modelling of the fugitive particulate matter from overburden dumps with numerical and integral models. Atmos Pollut Res 2:24-33

Citation details: Patra, A., Gautam, S., Majumdar, S., Kumar, P., 2015. Prediction of particulate matter concentration profile in an opencast copper mine in India using an artificial neural network model. Air Quality, Atmosphere \& Health, doi: 10.1007/s11869-015-0369-9. [PDF] 
Kassomenos P, Petrakis M, Sarigiannis D, Gotti A, Karakitsios S (2011) Identifying the contribution of physical and chemical stressors to the daily number of hospital admissions implementing an artificial neural network model. Air Qual Atmos Health 4:263-272.

Kumar A, Goyal P (2013) Forecasting of air quality index in Delhi using neural network based on principal component analysis. Pure Appl Geophy 170: 711-722.

Kumar P, Ketzel M, Vardoulakis S, Pirjola L, Britter R (2011) Dynamics and dispersion modelling of nanoparticles from road traffic in the urban atmospheric environment - a review. J Aero Sci 42: 580-603.

Lal B, Tripathy SS (2012) Prediction of dust concentration in open cast coal mine using artificial neural network. Atmos Pollut Res 3: 211-218.

Lu WZ, Wang WJ, Wang XK, Xu ZB, Leung AYT (2003) Using improved neural network model to analyze RSP, NOx and NO2 levels in urban air in MongKok, Hong Kong. Environ Monit Assess 87: 235-254.

Marrugo-Negrete JL, Urango-Cardenas ID, Núñez SMB, Díez S (2014) Atmospheric deposition of heavy metals in the mining area of the San Jorge river basin, Colombia. Air Qual Atmos Health 7: 577-588.

Masters GM (1998) Chapter 7: Air Pollution. Introduction to Environmental Engineering and Science (2nd Edition), New Delhi: Prentice Hall of India, pp. 392-405.

Nagendra SMS, Khare M (2004) Artificial neural network based line source models for vehicular exhaust emission predictions of an urban roadway. Transportation Resea Part D: Trans Environ 9 (3): 199-208.

Onder M, Yigit E (2009) Assessment of respirable dust exposures in an opencast coal mine. Environ Monit Assess 152: $393-401$.

Pandey B, Agrawal, M, Singh, S (2014) Assessment of air pollution around coal mining area: Emphasizing on spatial distributions, seasonal variations and heavy metals, using cluster and principal component analysis. Atmos Pollut Res 5: 79-86.

Peng X, Lu GR (1995) Physical modeling of natural wind and its guide in a large open pit mine. J Wind Engg Indu Aero 54-55: $473-81$.

Pless-Mulloli T, Howel D, Prince H (2001) Prevalence of asthma and other respiratory symptoms in children living near and away from opencast coal mining sites. Int J Epide 30 (3): 556-563.

Reggente M, Peters J, Theunis J, Poppel MV, Kumar P, De Baets B (2014) Prediction of ultrafine particle number concentration in urban environments by means of Gaussian process regression based on measurements of oxides of nitrogen. Environ Model Soft 61: 135-150.

Citation details: Patra, A., Gautam, S., Majumdar, S., Kumar, P., 2015. Prediction of particulate matter concentration profile in an opencast copper mine in India using an artificial neural network model. Air Quality, Atmosphere \& Health, doi: 10.1007/s11869-015-0369-9. [PDF] 
Richardson LF (1926) Atmospheric diffusion shown on a distance neighbour graph, Proceedings of the Royal Society of London. Series A 110: 709-737.

Guttikunda SK, Kopakka RV (2014) Source emissions and health impacts of urban air pollution in Hyderabad, India. Air Qual Atmos Health 7(2): 195-207.

Sharma P, Sharma P, Jain S, Kumar P (2013) A response to discussion on "An integrated statistical approach for evaluating the exceedence of criteria pollutants in the ambient air of megacity Delhi". Atmos Environ 71: 413-414.

Skön JP, Johansson M, Raatikainen M, Leiviskä K, Kolehmainen M (2012) Modelling indoor air carbon dioxide (CO2) concentration using neural network. World Academy of Science Eng Technol 61: 879-883.

Spectrum (2010) Operation manual of Watchdog 2000 series Portable Weather Station. Spectrum Technologies, Inc., USA

Tecer LH, Suren P, Alagha O, Karaca F, Tuncel G (2008) Effect of meteorological parameters on fine and coarse particulate matter mass concentration in a coal mining area in Zonguldak, Turkey. J Air Waste Manage Assoc 58: 543-552.

USEPA (1985) Dispersion of Airborne particulates in surface mines, 450/4-85-001.

Vardoulakis S, Fisher BEA, Pericleous K, Gonzalez-Flesca N (2003) Modelling air quality in street canyons: a review. Atmos Environ 37: 155-182

Viotti P, Liuti G,Genova PD (2002) Atmospheric urban pollution: application of an artificial neural network (ANN) to the city of Perugia. Ecolog Model 148: 27-46.

Zhang X, Chen W, Ma C, Zhan S (2013) Modeling particulate matter emissions during mineral loading process under weak wind simulation. Sci Tot Environ 449: 168-173.

\section{List of figure captions}

Citation details: Patra, A., Gautam, S., Majumdar, S., Kumar, P., 2015. Prediction of particulate matter concentration profile in an opencast copper mine in India using an artificial neural network model. Air Quality, Atmosphere \& Health, doi: 10.1007/s11869-015-0369-9. [PDF] 
Fig.1. Study location at MCP.

Fig. 2. Neural interpretation structure for prediction of PM concentrations.

Fig. 3. Wind speed at MCP.

Fig. 4. Wind speed distribution at MCP.

Fig. 5. Wind directions at MCP.

Fig. 6. Ambient temperature profile at MCP.

Fig. 7. Relative humidity at MCP.

Fig. 8. PM concentration profile at MCP: (a) Background concentration; (b) Incremental concentration

Fig. 9. PM concentration at different depths: Model prediction vs. measurement.

Fig. 10. Estimates of absolute error of ANN model prediction.

Fig. 11. Regression plot of ANN model output 


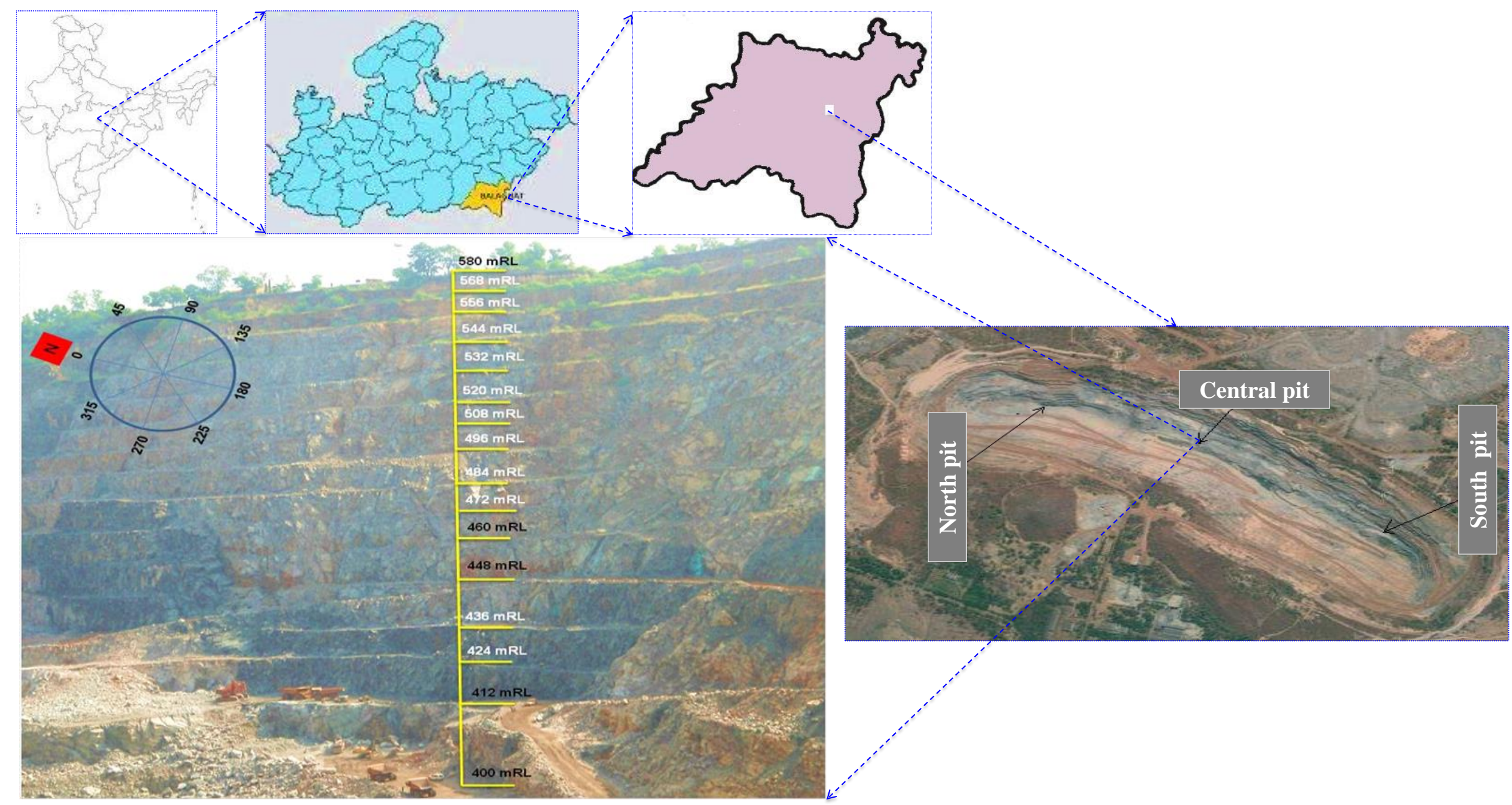

Fig.1.

Citation details: Patra, A., Gautam, S., Majumdar, S., Kumar, P., 2015. Prediction of particulate matter concentration profile in an opencast copper mine in India using an artificial neural network model. Air Quality, Atmosphere \& Health, doi: 10.1007/s11869-015-0369-9. [PDF] 


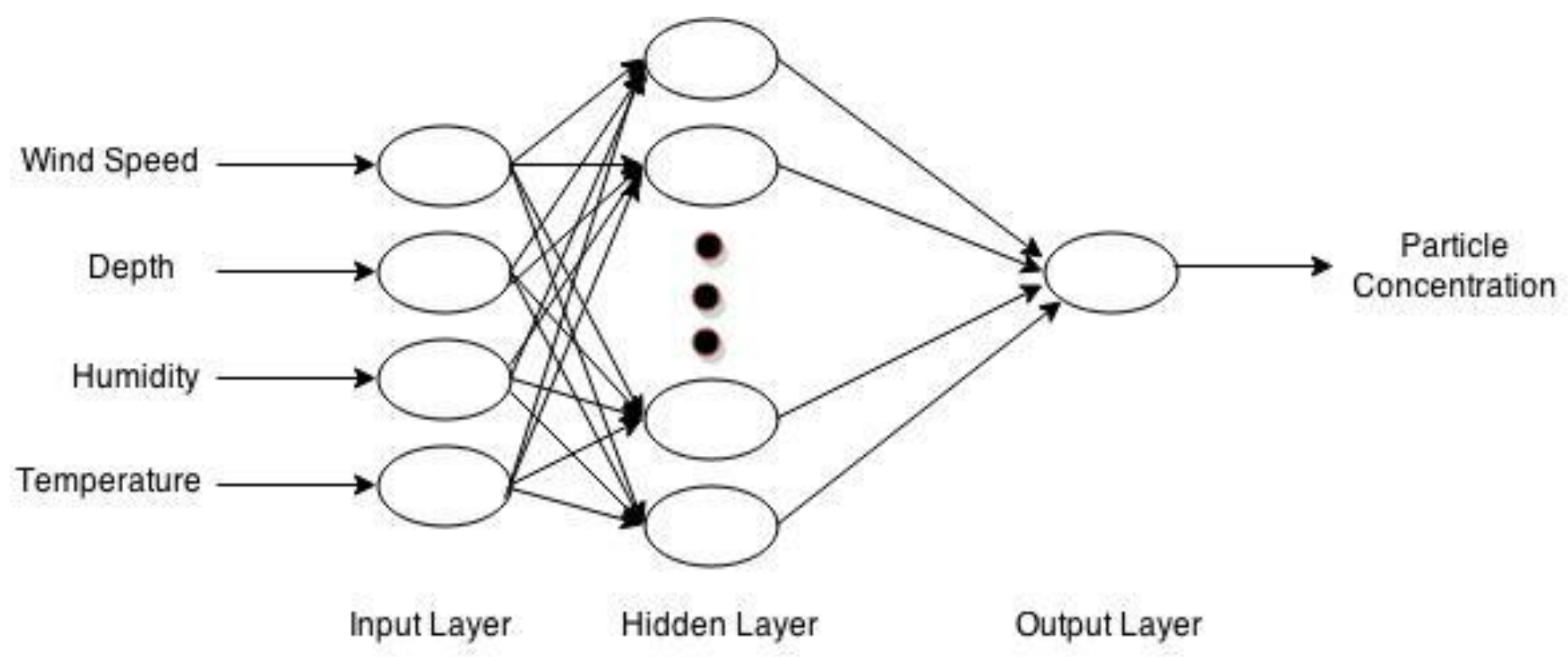

Fig. 2.

Citation details: Patra, A., Gautam, S., Majumdar, S., Kumar, P., 2015. Prediction of particulate matter concentration profile in an opencast copper mine in India using an artificial neural network model. Air Quality, Atmosphere \& Health, doi: 10.1007/s11869-015-0369-9. [PDF] 

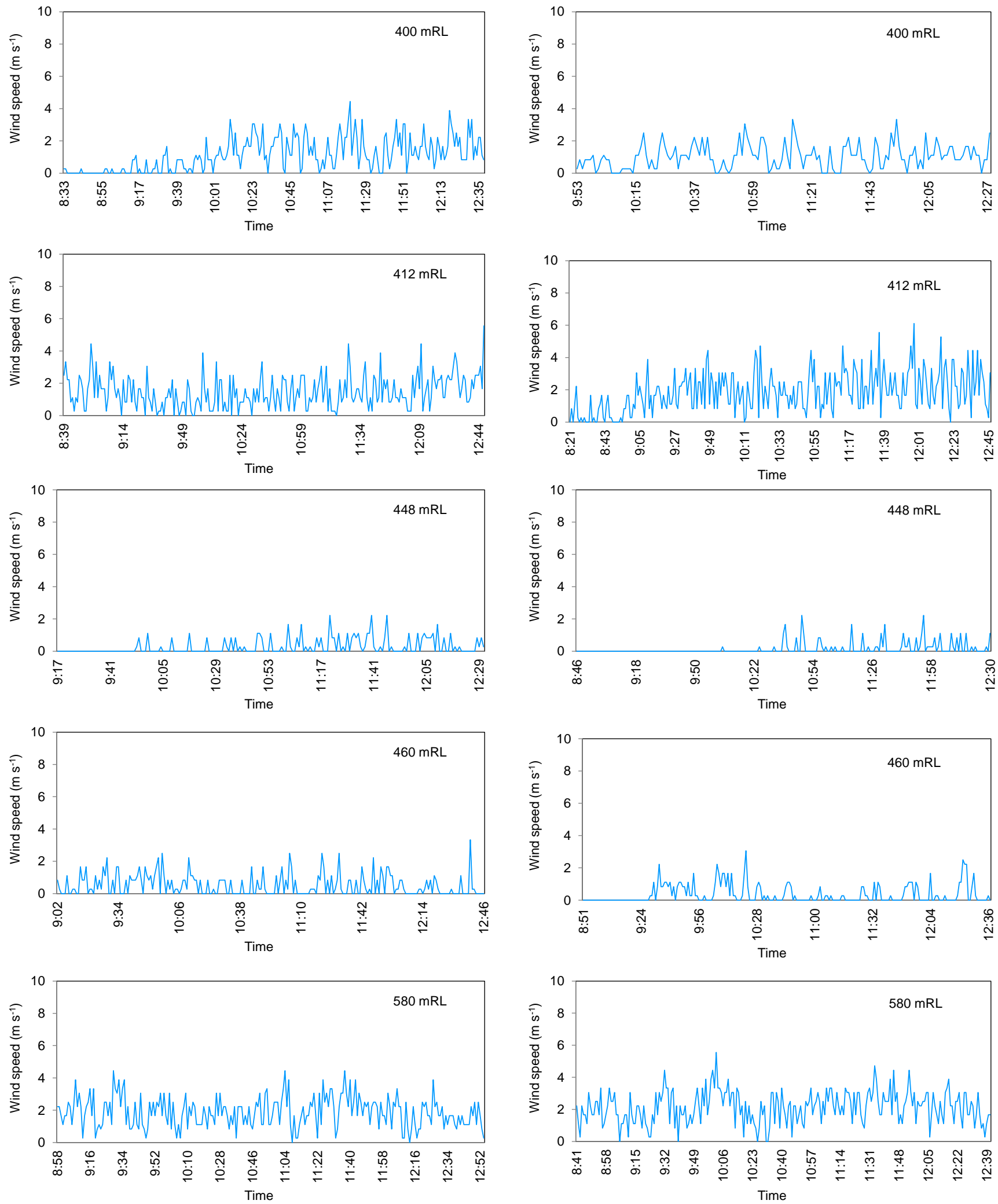

Fig. 3.

Citation details: Patra, A., Gautam, S., Majumdar, S., Kumar, P., 2015. Prediction of particulate matter concentration profile in an opencast copper mine in India using an artificial neural network model. Air Quality, Atmosphere \& Health, doi: 10.1007/s11869-015-0369-9. [PDF] 

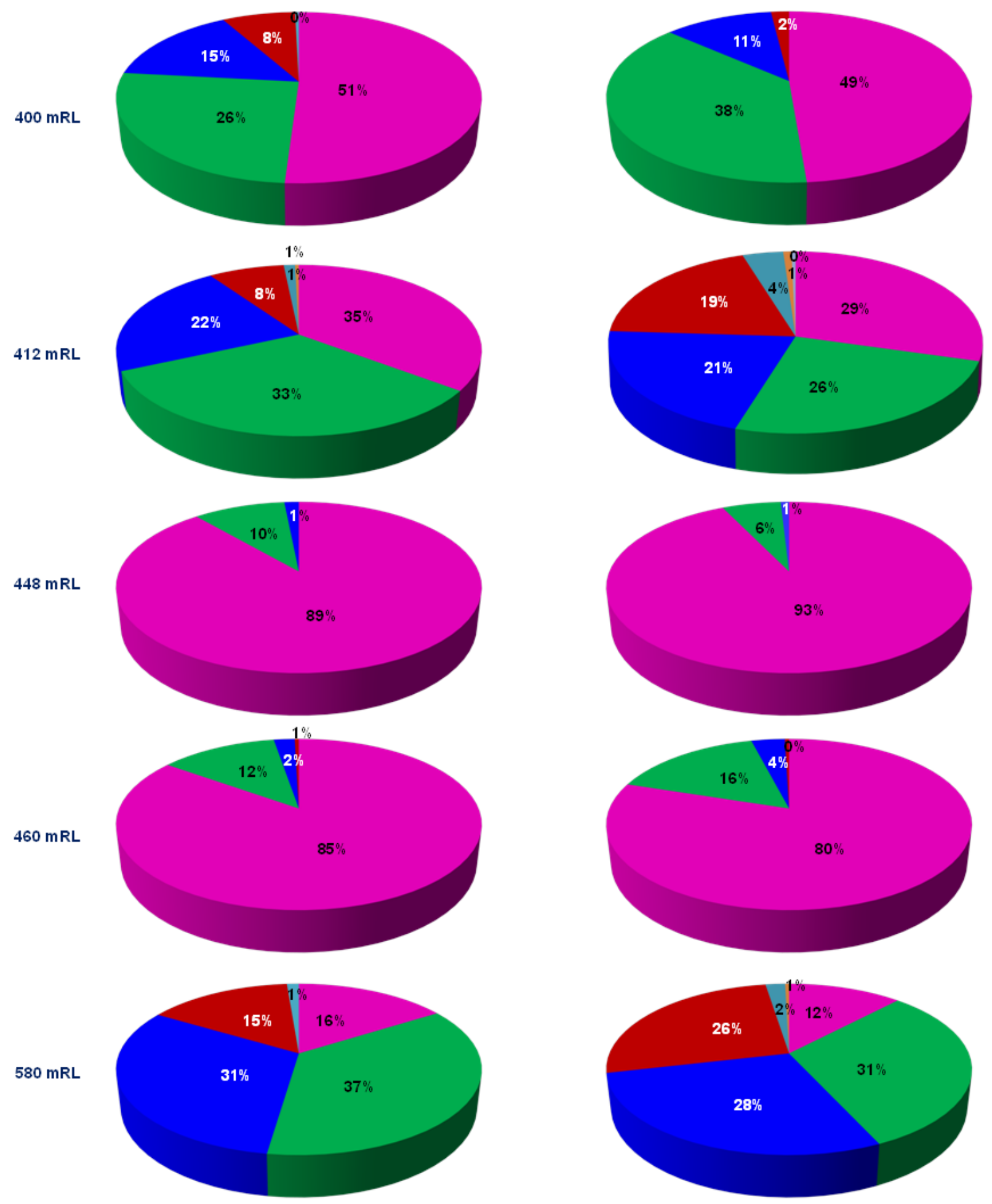

$=0-1 \quad=1-2 \quad=2-3 \quad=3-4=4-5 \quad \square-6=6-7$

Fig. 4.

Citation details: Patra, A., Gautam, S., Majumdar, S., Kumar, P., 2015. Prediction of particulate matter concentration profile in an opencast copper mine in India using an artificial neural network model. Air Quality, Atmosphere \& Health, doi: 10.1007/s11869-015-0369-9. [PDF] 

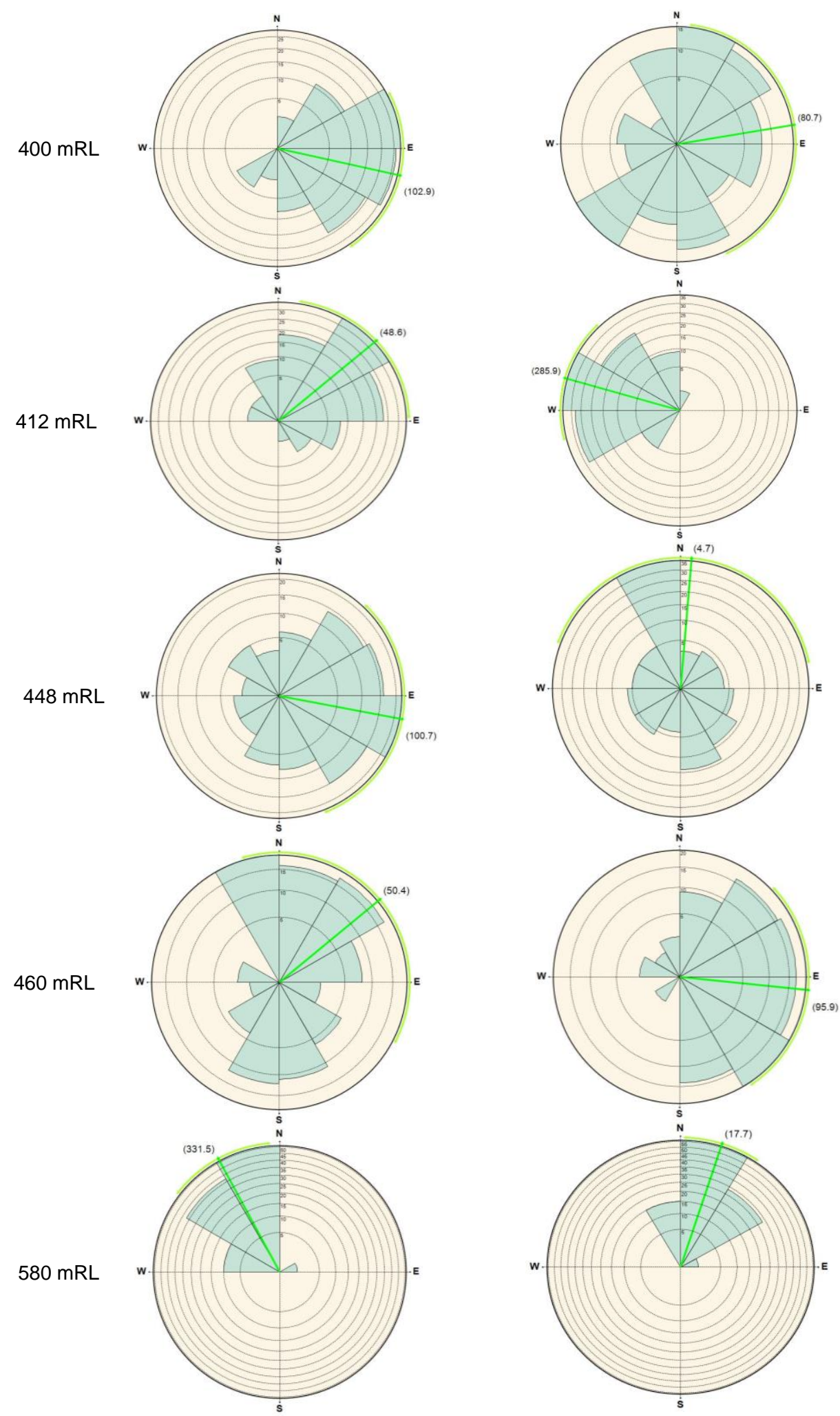

Fig. 5.

Citation details: Patra, A., Gautam, S., Majumdar, S., Kumar, P., 2015. Prediction of particulate matter concentration profile in an opencast copper mine in India using an artificial neural network model. Air Quality, Atmosphere \& Health, doi: 10.1007/s11869-015-0369-9. [PDF] 

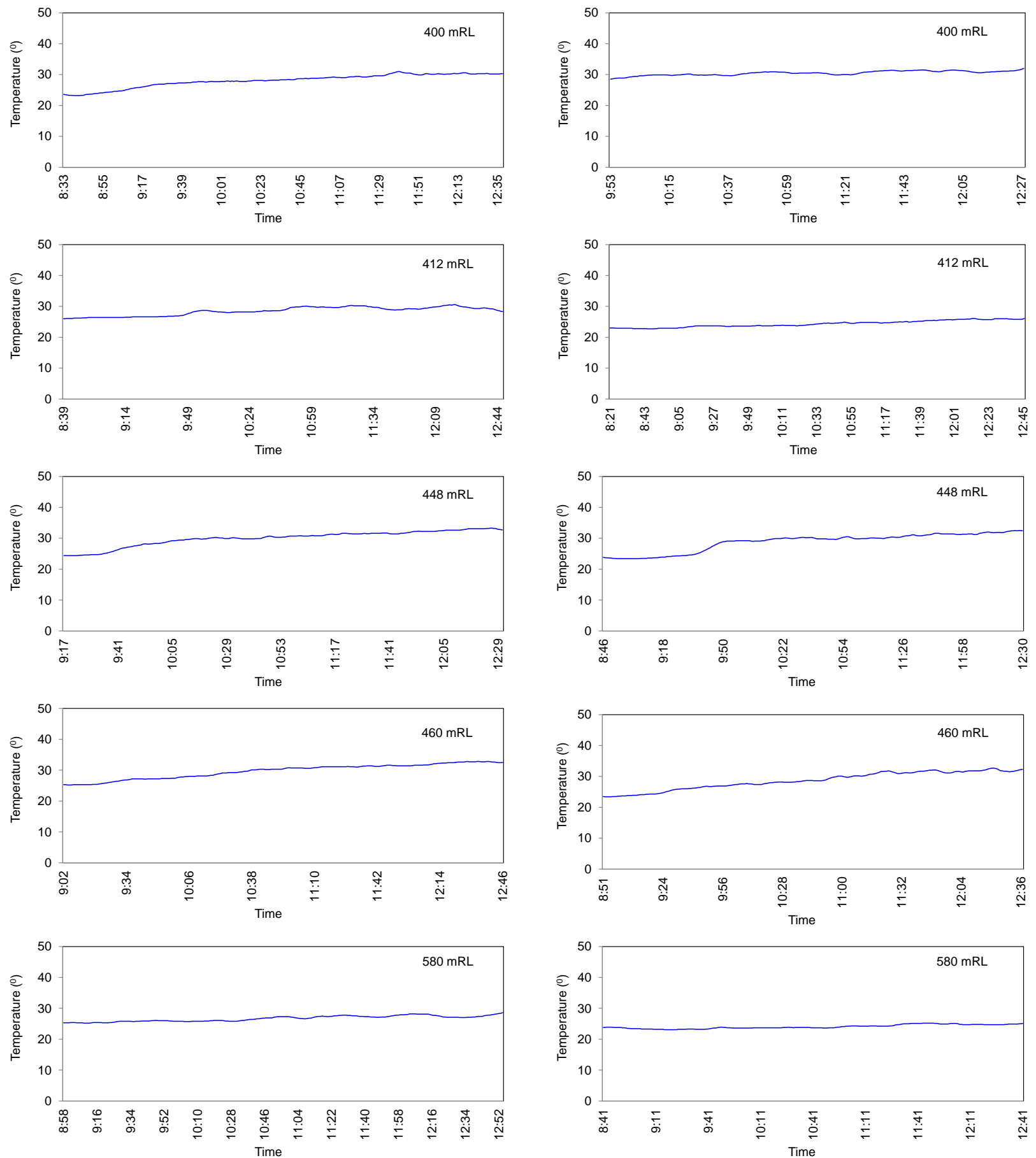

Fig. 6.

Citation details: Patra, A., Gautam, S., Majumdar, S., Kumar, P., 2015. Prediction of particulate matter concentration profile in an opencast copper mine in India using an artificial neural network model. Air Quality, Atmosphere \& Health, doi: 10.1007/s11869-015-0369-9. [PDF] 

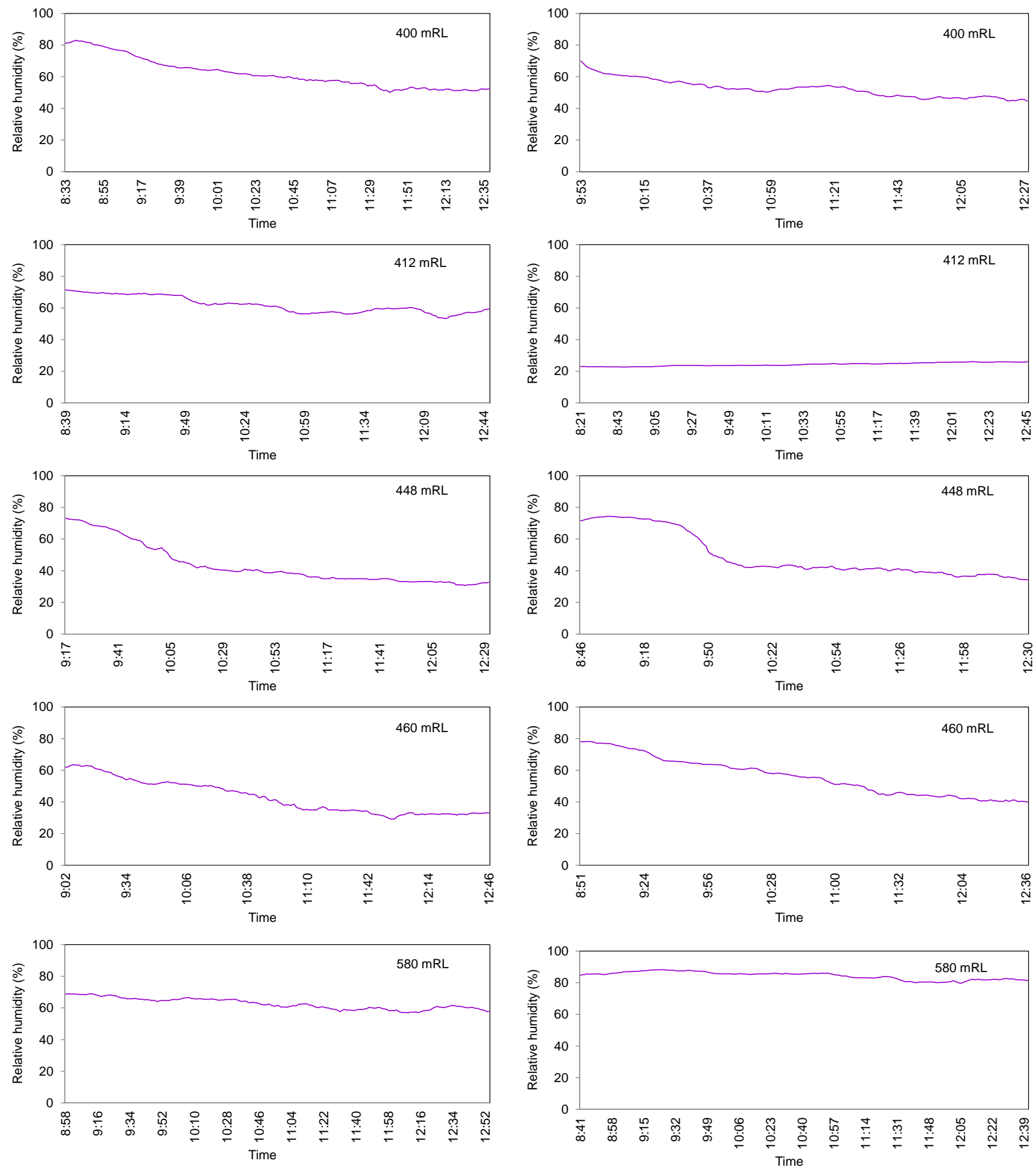

Fig. 7.

Citation details: Patra, A., Gautam, S., Majumdar, S., Kumar, P., 2015. Prediction of particulate matter concentration profile in an opencast copper mine in India using an artificial neural network model. Air Quality, Atmosphere \& Health, doi: 10.1007/s11869-015-0369-9. [PDF] 


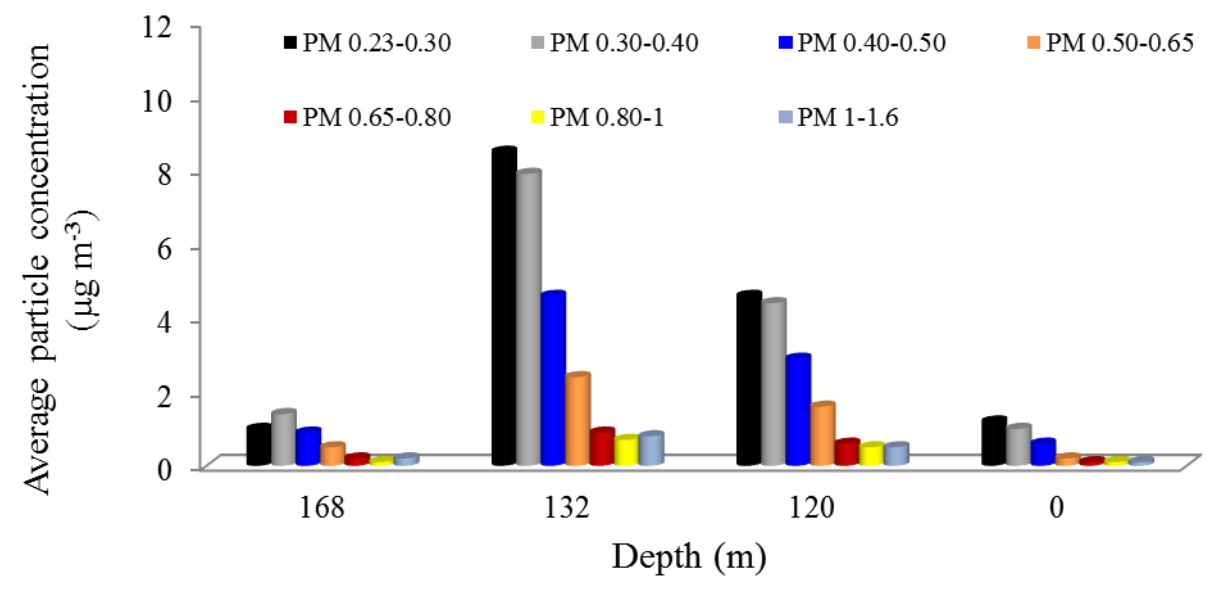

(a)

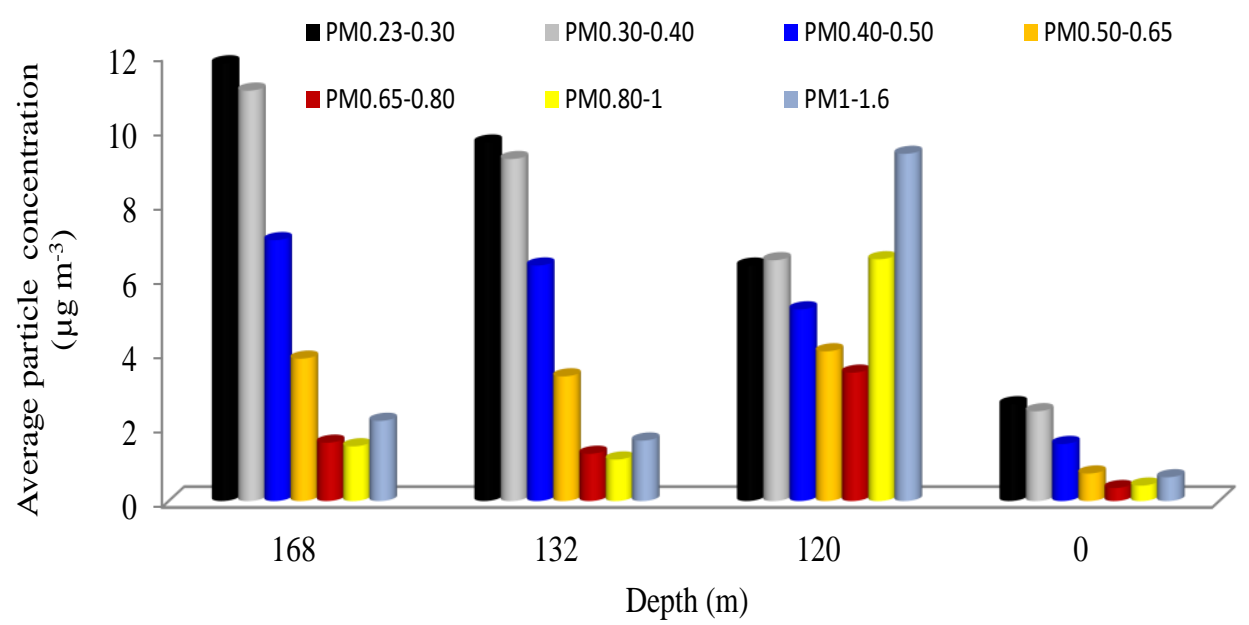

(b)

Fig. 8.

Citation details: Patra, A., Gautam, S., Majumdar, S., Kumar, P., 2015. Prediction of particulate matter concentration profile in an opencast copper mine in India using an artificial neural network model. Air Quality, Atmosphere \& Health, doi: 10.1007/s11869-015-0369-9. [PDF] 


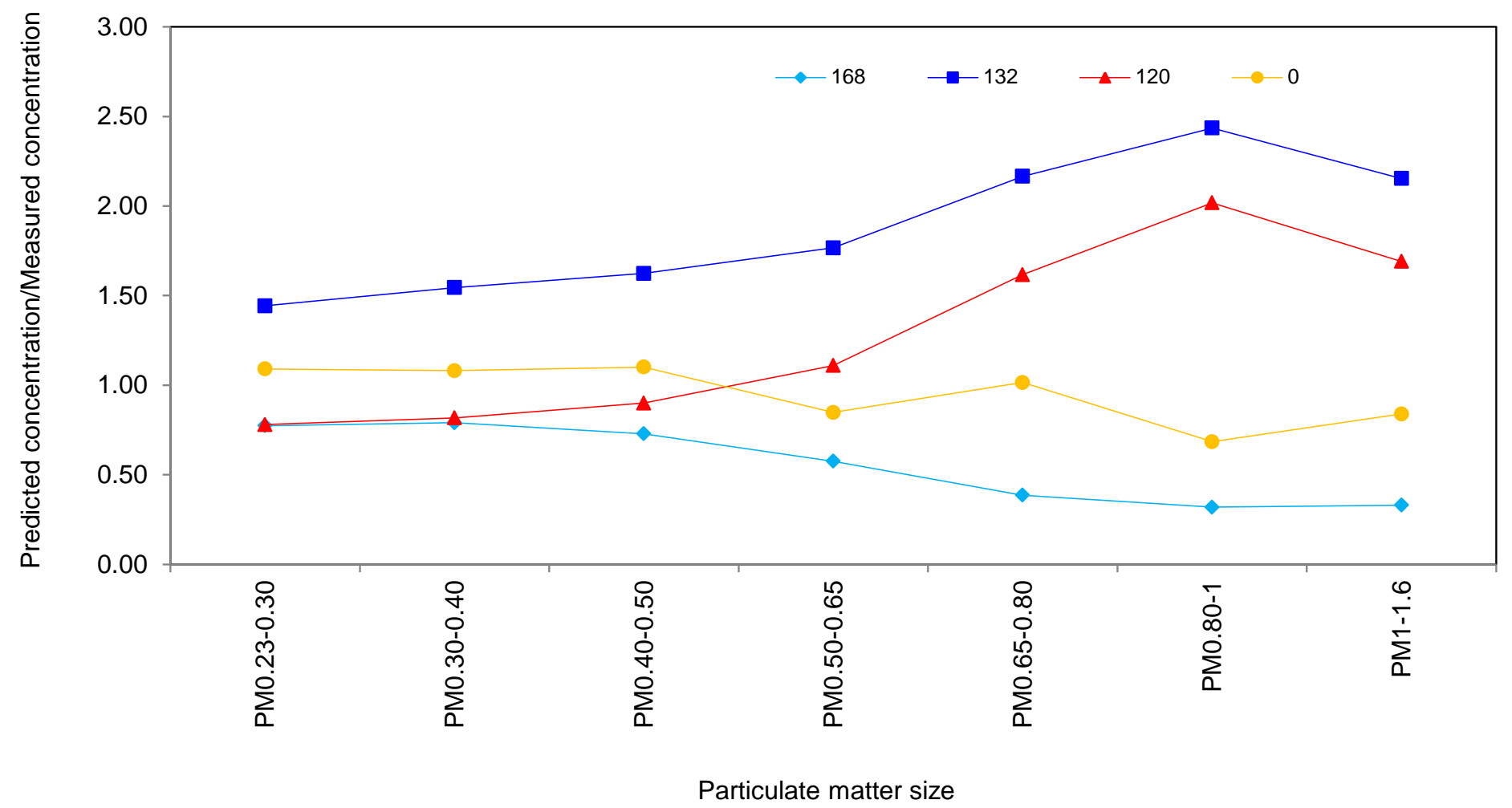

Fig. 9.

Citation details: Patra, A., Gautam, S., Majumdar, S., Kumar, P., 2015. Prediction of particulate matter concentration profile in an opencast copper mine in India using an artificial neural network model. Air Quality, Atmosphere \& Health, doi: 10.1007/s11869-015-0369-9. [PDF] 

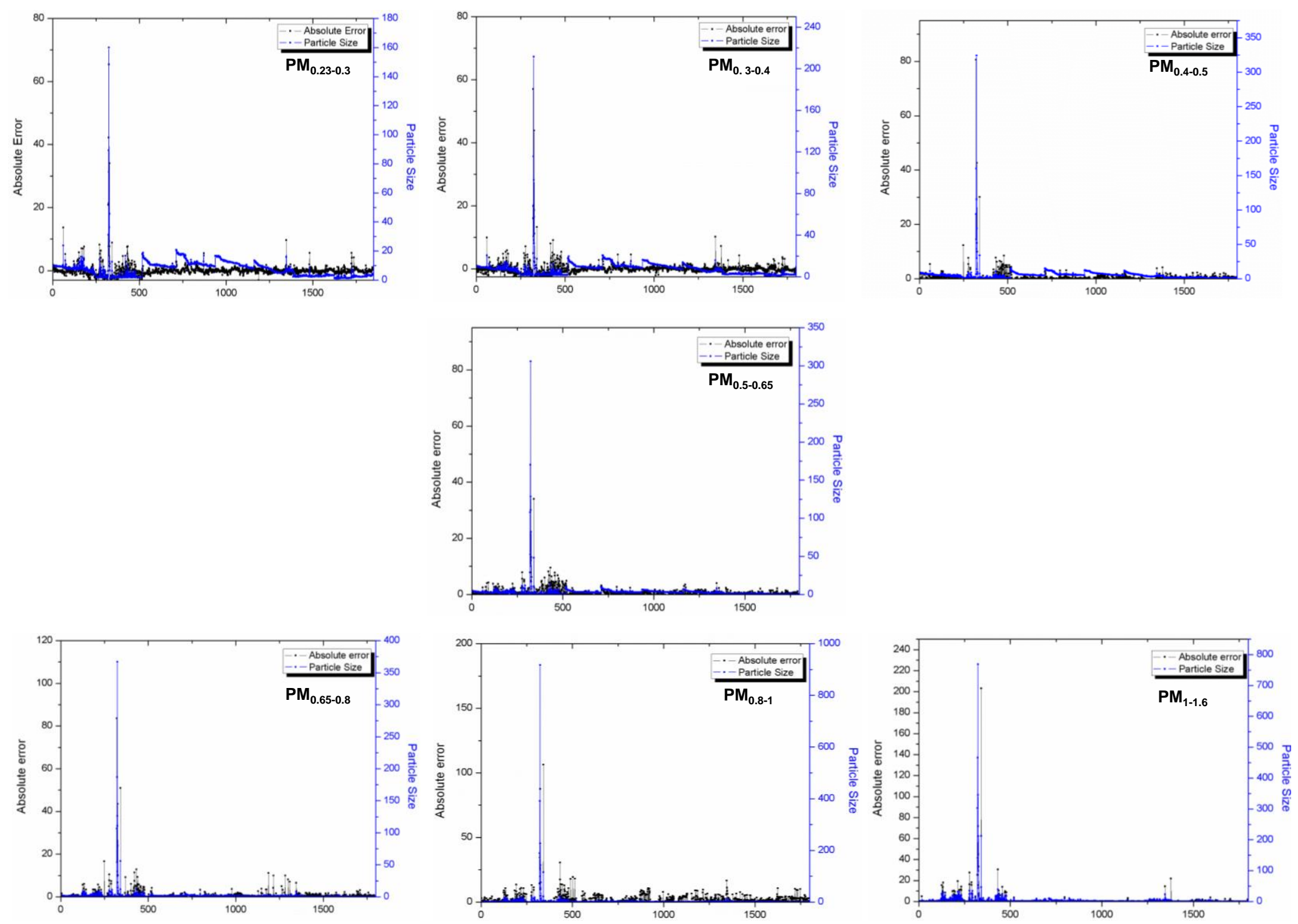

Fig.10.

Citation details: Patra, A., Gautam, S., Majumdar, S., Kumar, P., 2015. Prediction of particulate matter concentration profile in an opencast copper mine in India using an artificial neural network model. Air Quality, Atmosphere \& Health, doi: 10.1007/s11869-015-0369-9. [PDF] 

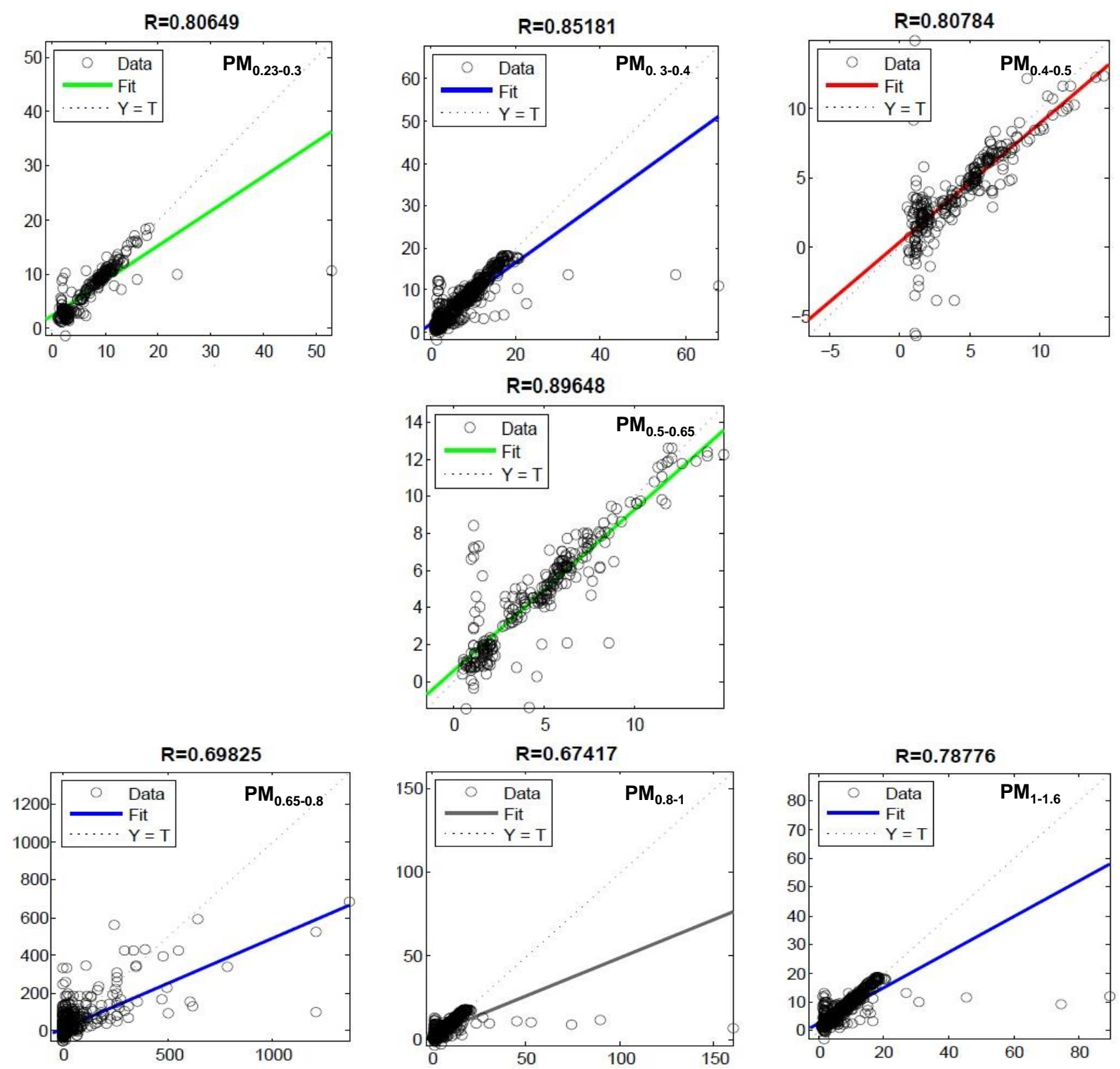

Fig.11.

Citation details: Patra, A., Gautam, S., Majumdar, S., Kumar, P., 2015. Prediction of particulate matter concentration profile in an opencast copper mine in India using an artificial neural network model. Air Quality, Atmosphere \& Health, doi: 10.1007/s11869-015-0369-9. [PDF] 
Table 1 Relationships between concentration of PM and depth

\begin{tabular}{cccc}
\hline \multicolumn{1}{c}{ PM } & Predictor Equations & $R^{2}(\%)$ & \multicolumn{1}{c}{ Parameters } \\
$\mathrm{PM}_{0.23-0.30}$ & $y=1.721 e^{0.005 x}$ & 64.8 & \\
$\mathrm{PM}_{0.30-0.40}$ & $y=1.695 e^{0.005 x}$ & 59.2 & $x=$ Depth $(\mathrm{m})$ \\
$\mathrm{PM}_{0.40-0.50}$ & $y=1.118 e^{0.006 x}$ & 61.2 & \\
$\mathrm{PM}_{0.50-0.65}$ & $y=0.485 e^{0.009 x}$ & 65.3 & \\
$\mathrm{PM}_{0.65-0.80}$ & $y=0.272 e^{0.010 x}$ & 46.7 & \\
$\mathrm{PM}_{0.80-1}$ & $y=0.230 e^{0.014 x}$ & 52.8 & \\
$\mathrm{PM}_{1-1.6}$ & $y=0.475 e^{0.012 x}$ & 52.6 & \\
\hline
\end{tabular}


Table 2 Best network architectures for each particle dataset

\begin{tabular}{|c|c|c|c|c|c|c|c|c|c|}
\hline Net. name & $\begin{array}{c}\text { Training } \\
\text { performance }\end{array}$ & $\begin{array}{c}\text { Test } \\
\text { performance }\end{array}$ & $\begin{array}{l}\text { Training } \\
\text { error }\end{array}$ & Test error & $\begin{array}{l}\text { Training algorithm / } \\
\text { epoch numbers }\end{array}$ & $\begin{array}{l}\text { Error } \\
\text { function }\end{array}$ & $\begin{array}{l}\text { Hidden } \\
\text { activation }\end{array}$ & $\begin{array}{c}\text { Output } \\
\text { activation }\end{array}$ & Output \\
\hline MLP 4-35-1 & 0.82 & 0.67 & 0.0032 & 0.0043 & TRAINLM/ 67 & SOS & Tanh & Identity & $\mathrm{PM}_{0.23-0.3}$ \\
\hline MLP 4-25-1 & 0.71 & 0.65 & 0.0023 & 0.003 & TRAINLM/ 45 & SOS & Tanh & Identity & $\mathrm{PM}_{0.3-0.4}$ \\
\hline MLP 4-55-1 & 0.79 & 0.63 & 0.0025 & 0.0031 & TRAINLM/ 17 & SOS & Tanh & Identity & $\mathrm{PM}_{0.4-0.5}$ \\
\hline MLP 4-35-1 & 0.75 & 0.69 & 0.0035 & 0.0035 & TRAINLM/ 19 & SOS & Tanh & Identity & $\mathrm{PM}_{0.5-0.65}$ \\
\hline MLP 4-35-1 & 0.8 & 0.71 & 0.0022 & 0.0023 & TRAINLM/ 23 & SOS & Tanh & Identity & $\mathrm{PM}_{0.65-0.8}$ \\
\hline MLP 4-29-1 & 0.85 & 0.6 & 0.009 & 0.006 & TRAINLM/ 35 & SOS & Tanh & Identity & $\mathrm{PM}_{0.8-1}$ \\
\hline MLP4-60-1 & 0.56 & 0.67 & 0.01 & 0.009 & TRAINLM/32 & sos & Tanh & Identity & $\mathrm{PM}_{1-1}$ \\
\hline
\end{tabular}

